\title{
HAEMANGIO-ENDOTHELIOMA WITH HAEMORRHAGE AND THROMBOCYTOPENIA
}

\author{
BY \\ A. WHITE FRANKLIN and D. A. J. WILLIAMSON \\ From St. Bartholomew's Hospital, London, and the Southampton Children's Hospital
}

(RECEIVED FOR PUBLICATION AUGUST 5, 1953)

Two infants have recently been observed with haemangiomata into which gross and dangerous bleeding occurred, associated with thrombocytopenia. The naevus, in the form of the port-wine stains and strawberry naevi, is a common benign condition, fading or disappearing with the years and with or without treatment. That it should at times, and in the cases described below, be a menace to life either from haemorrhage or from malignancy raises controversial points in histology.

The association of haemangioma, haemorrhage and thrombocytopenia has already been reported on at least three occasions. Kasabach and Merritt (1940) described such a case in which a purple swelling appeared on the thigh of an infant 1 week old, slowly spreading to involve the buttock and scrotum. At the age of 9 weeks haemorrhage occurred into the swelling, part of which became necrotic, and petechiae were observed over the abdominal wall. Biopsy confirmed the clinical diagnosis of capillary haemangioma. Blood examination revealed increasing anaemia and considerable thrombocytopenia. The platelet count fell to 16,000 per c.mm. and both bleeding and clotting times were markedly prolonged. After several blood transfusions had been given the lesion responded successfully to radiotherapy, and the boy was in good health with a normal blood picture at the age of $2 \frac{1}{2}$ years.

In the case of Rhodes and Borrelli (1944) the haemangioma, present at birth, gradually spread to involve the lower part of the head and face, the neck, shoulder and upper part of the thorax on the left side. Haemorrhagic spots were seen around the pharynx and the baby's cry became laryngeal. At 2 months numerous ecchymoses and petechiae were noted all over the body; anaemia was moderate, thrombocytopenia considerable (platelets, 15,000 per c.mm.), and the bleeding time was greatly prolonged. The biopsy pathological diagnosis was haemangio-endothelioma. With treatment by repeated blood transfusions and radiotherapy the size of the tumour lessened and the haematological picture improved. Silver, Aggeler and Crane (1948) describe the case of a female infant with a small vascular tumour behind the right ear at birth. Similar small tumours appeared in other situations later. At the age of 5 months a large tumour was observed on the back, it did not respond to radiotherapy, and gradually spread over a large area of the thorax, shoulder, neck and back of the head. The blood picture, normal at first, later showed anaemia and thrombocytopenia (platelets, 32,000 per c.mm.) with prolonged bleeding time. In the course of the case there were generalized petechiae and ecchymoses, haemorrhages into the substance of the tumour, a large haemothorax and death. Necropsy findings showed an extensive capillary and cavernous haemangio-endothelioma involving skin, subcutaneous tissue, striated muscle. thyroid capsule and parietal pleura.

\section{Case Reports}

Case 1. Ian K. was born at term on December 24 . 1946. The delivery was difficult, but the baby appeared normal at birth, weight being about $6 \mathrm{lb}$. At the age of 6 days a swelling appeared in the right side of the neck and rapidly increased in size. The overlying skin was a deep purple and this discoloration extended down over the right shoulder. There was no constitutional disturbance and the swelling slowly subsided. The baby was discharged home on the eighteenth day, artificially fed and weighing $5 \mathrm{lb}$. $10 \mathrm{oz}$. At 5 weeks old some subcutaneous lumps could be felt in the right side of the neck, and the skin remained slightly discoloured. At the age of 3 months he was re-admitted to hospital as an emergency case with the history that four days previously further swelling and bruising had been noted in the original place, extending over the right shoulder. The swelling steadily increased in size and began to cause respiratory distress. Examination revealed a discoloured swelling like a large haematoma, and occupying the anterior triangle of the right side of the neck, extending up on to the right cheek, over the right clavicle and out over the right shoulder (Figs. 1 and 2). The swelling continued to 


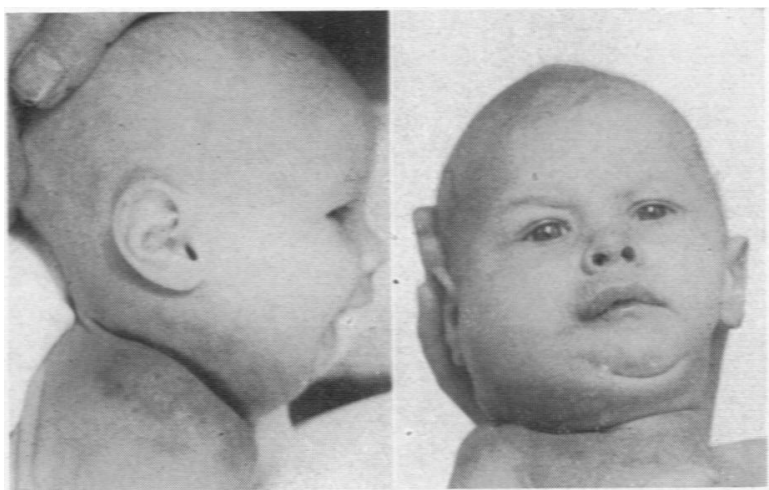

FKGS. 1 and 2. Case 1, aged 4 months, (25.4.47) showing original mass in the neck in antero-posterior and lateral views.

increase in size with further respiratory distress and stridor. Aspiration produced fresh blood. After four days the head and neck were immobilized in a plaster cast, and $100 \mathrm{ml}$. of blood was transfused. Following the transfusion there was no further bleeding, but the swelling altered little in size and after three weeks in hospital the baby was transferred to St. Bartholomew's Hospital for treatment with deep $x$-rays. Four local treatments each of $200 \mathrm{r}$ were given. The swelling was somewhat reduced but there was no dramatic change at the time. Three weeks after the last treatment a number of small subcutaneous swellings appeared under the skin on the legs and buttocks. Biopsy and section of one of them showed it to be a small capillary haemangioma without any evidence of malignancy. At the age of 6 months the baby was sent home still with considerable swelling in the neck. Blood examinations are recorded in Table 1. At the age of 9 months he was examined and found to have a large mass on the right side of the neck extending from behind the mastoid process forwards into the neck' and over the upper sternum with marked inspiratory recession of the lower ribs. The spleen was not felt though the liver was enlarged (three fingerbreadths). There had been a few fresh subcutaneous haemangiomata on the left side of the abdomen and the left thigh. At 10 months the baby weighed $13 \mathrm{lb} .10 \mathrm{oz}$. The mucous membranes were pale and the mass was thought to be enlarging. He was therefore re-admitted to St. Bartholomew's Hospital for another course of deep $\mathrm{x}$-ray treatment which this time was followed by great improvement (10 treatments of 200 r, 190 m.v.). Again fresh haemangiomata developed on the limbs during and after this treatment, and there was a slow but steady improvement. At the age of 2 years he weighed $22 \mathrm{lb}$., but though small was talking and walking and behaving normally. All the subcutaneous tumours had disappeared. At the site of the swelling the subcutaneous tissues had become atrophic and the skin remained discoloured resembling a fading haemangioma. At the age of $3 \frac{1}{2}$ years he weighed $28 \mathrm{lb}$. and seemed to be normal except for the signs described on the right side of the neck (Figs. 3 and 4). At the age of 6 years he is a well-grown, healthy boy but the skin of the right side of the neck is discoloured and atrophic, and there is some limitation of movement of the neck, the head being held over towards the affected side.

The radiographs of the neck, chest and shoulder show a peculiar shape of the right clavicle at the age of 9 days (Fig. 5) and later some rarefaction of the outer end of the right clavicle and of the head of the right humerus, together with irregular subperiosteal bone formation (Figs. 5, 6 and 7).

Case 2. Kenneth P. was born on April 10, 1951, following a normal pregnancy and delivery. The birth weight was $8 \mathrm{lb}$. At birth a large, soft-tissue swelling was noted on the left side of the neck extending downwards over the left shoulder and upwards to the left ear which

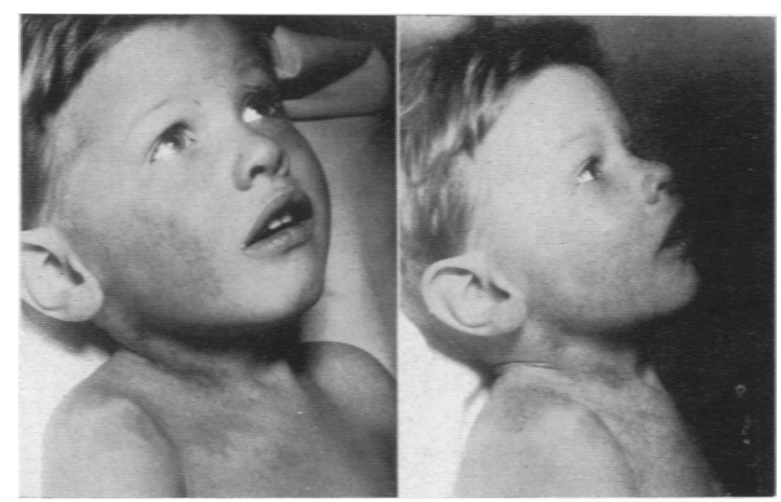

Figs. 3 and 4.-Case 1, aged 3 years 4 months (22.4.50), after treatment showing discoloured and atrophic skin.

TABLE 1

BLOOD EXAMINATION OF CASE 1 (BORN 24.12.46)

\begin{tabular}{|c|c|c|c|c|c|c|c|}
\hline Date & $\mathrm{Hb}$ \% (g.) & $\begin{array}{c}\text { R.B.C. } \\
\text { (m/c.mm.) }\end{array}$ & C.I. & $\begin{array}{c}\text { W.B.C. } \\
\text { (per c.mm.) }\end{array}$ & $\begin{array}{c}\text { Platelets } \\
\text { (per c.mm.) }\end{array}$ & $\begin{array}{c}\text { Clotting Time } \\
\text { (min.) }\end{array}$ & $\underset{\text { (min.) }}{\text { Bleeding Time }}$ \\
\hline $\begin{array}{r}25.3 .47 \\
28.3 .47 \\
8.4 .47 \\
16.4 .47 \\
24.6 .47 \\
20.10 .47 \\
28.2 .49 \\
4.4 .50\end{array}$ & $\begin{array}{l}84(11 \cdot 6) \\
48(6 \cdot 6) \\
53(7 \cdot 3) \\
70(9 \cdot 7) \\
70(9 \cdot 7) \\
70(9 \cdot 7) \\
92(12 \cdot 88) \\
88(12 \cdot 32)\end{array}$ & $\begin{array}{l}3 \cdot 71 \\
2 \cdot 27 \\
3 \cdot 40 \\
3 \cdot 78 \\
3 \cdot 50 \\
3 \cdot 43 \\
4 \cdot 27\end{array}$ & $\begin{array}{l}1 \cdot 07 \\
1 \cdot 09 \\
1 \cdot 06 \\
0 \cdot 9 \\
1 \cdot 0 \\
1 \cdot 0 \\
0 \cdot 9\end{array}$ & $\begin{array}{r}13,750 \\
11,000 \\
4,700 \\
7,000 \\
63,000 \\
5,000\end{array}$ & $\begin{array}{r}124,850 \\
22,000 \\
50,000 \\
4,000 \\
133,000 \\
298,000\end{array}$ & $\begin{array}{l}1 \frac{1}{2} \\
\frac{2}{2} \\
21 \\
6\end{array}$ & $\begin{array}{c}31 \\
21 \\
9 \\
20 \\
10- \\
9 ! \\
4 \frac{1}{2}\end{array}$ \\
\hline
\end{tabular}




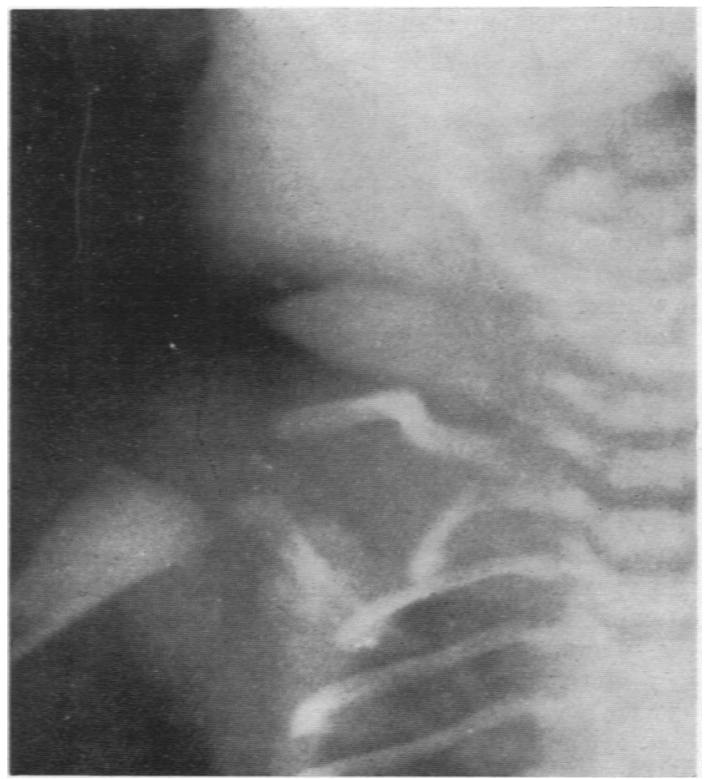

FiG. 5.-Case 1, aged 9 days, showing aboormal clavicle.

was displaced. The consistency of the swelling was soft but there were a number of firm, bluish nodules in its substance. The skin overlying the tumour was markedly oedematous. Associated with the swelling was a degree of micrognathia and the palatal arch was high. Apart from some difficulty in sucking, probably due to the micrognathia, the infant's progress gave rise to no anxiety during the immediate post-natal period. The swelling, which was

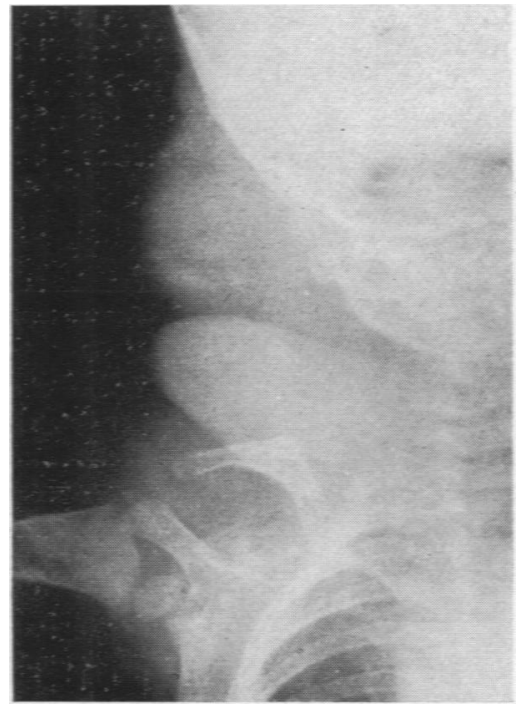

Fig. 6. Case 1 aged 10 months. thought to be a haemangioma, became very much smaller and the baby was discharged home with his mother on the twelfth day of life. The rapid reduction in the size of the tumour appeared to be due to extensive thrombosis within the haemangioma. The tumour remained relatively small and the baby made normal progress until the age of 4 weeks. On May 7 there was a rapid increase in the size of the swelling during the night. When seen next morning the baby was pale and distressed with a slight stridor. On the left side of the neck there was a huge tense, blue haematoma extending upwards to involve the left cheek, mandible and the lower half of the pinna and downwards to the level of the second costal cartilage (Figs. 8, 9, 10). In the neck the swelling crossed the midline anteriorly. Examination of the blood showed prolongation of both bleeding and clotting times (both over 20 minutes) with severe thrombocytopenia (platelets, 10,000 per c.mm.) and anaemia (haemoglobin $52 \%(7 \cdot 7 \mathrm{~g} . \%$ )).

He was given vitamin $K, 10 \mathrm{mg}$., twice daily and at first his condition seemed to improve. The stridor disappeared after 24 hours and some thrombosis appeared to be occurring in the swelling. Four days later, however, the stridor reappeared and the breathing became distressed and irregular. In spite of the usual restorative measures the child died.

Post-mortem examination showed the body of a wellnourished infant. There was a bluish swelling on the left side of the neck as described above. On dissection the haemangioma was found to involve not only the skin and the subcutaneous tissues but the muscles of the neck, the epiglottis, both the true and false vocal cords in the larynx and the surrounding soft tissues. Apart from some basal congestion in the lungs the remaining organs were normal. Death was ascribed to asphyxia. Histological section showed the tumour to be a highly vasoformative haemangio-endothelioma, clearly infiltrating neighbouring muscle (Fig. 11).

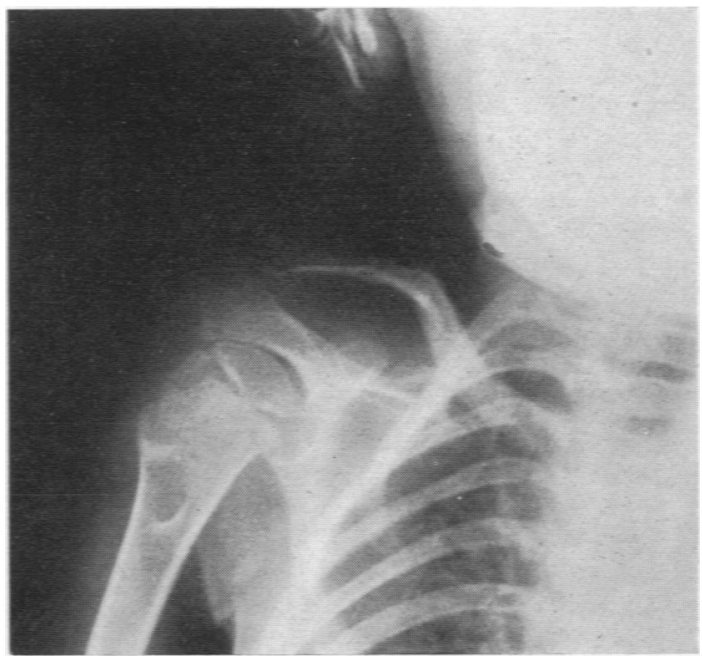

FiG. 7.-Case 1, aged 4 years 6 months, showing rarefaction and irregularity of the clavicle. 


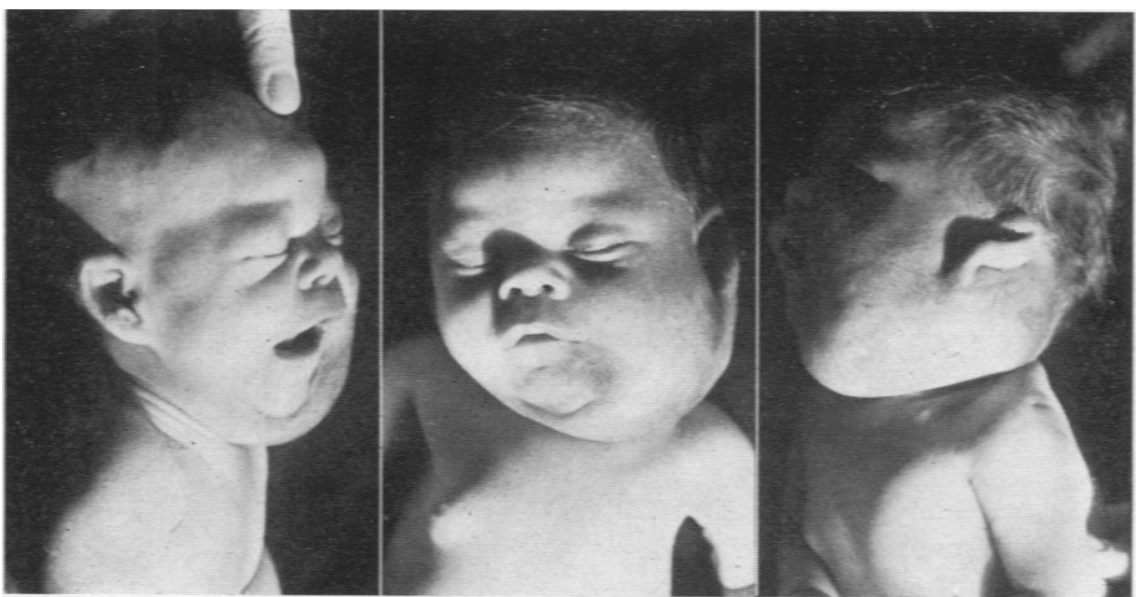

Figs. 8, 9, 10.-Case 2, Original mass in the neck with discoloration of the skin.

years ago, the lump having first suddenly appeared five years ago. The right shoulder region was irradiated after the operation.

Haemangio-endothelioma is the name used by the authors whose cases are quoted above. In our fatal Case 2 the histology proves local infiltration into muscle, and the diagnosis is haemangio-endothelioma without metastasis. Our first

\section{Discussion}

The classification of haemangiomata is made difficult by variations in the histological appearances of different parts of the same lesion. In some cases there is undoubted infiltration into neighbouring tissues, establishing the fact of local malignancy. Other cases raise the problem of metastatic spread. A simple solution is to regard the common capillary or cavernous haemangioma as a congenital developmental defect of blood vessels, naming it a hamartoma and contrasting it with a true tumour, the haemangio-endothelioma, which has malignant potentialities of local infiltration, of recurrence and of metastatic spread. When the lesion is first observed there seems no way of making a clinical distinction which must await either the evolution of the case or a biopsy. Stout (1943) after a careful review of his own and of reported cases concluded that he could recognize the true tumour, the haemangio-endothelioma, by finding (1) atypical endothelial cells in greater numbers than were needed to line vessels with a simple endothelial lining, and (2) a delicate anastomosing framework of reticulin fibres outlining vascular tubes though concealed by masses of endothelial cells. In his view metastasis and local infiltration only occur with true haemangioendothelioma. Among the cases described (Stout, 1943 ) is one of a man of 25 years with a haemangioendothelioma in the supraclavicular fossa, successfully excised. Three years after operation metastases appeared in bone and one year later in the lungs. Five years after the original excision the patient died. Mr. J. P. Hosford allows us to quote the case of a girl now alive, well and without sign of recurrence at the age of 11 years from whose right supra-clavicular fossa he excised a haemangio-endothelioma three case raises the problem of metastasis in a new way. Sections of one of the small subcutaneous tumours whose appearance followed radiotherapy shows a typical capillary haemangioma, a diagnosis in

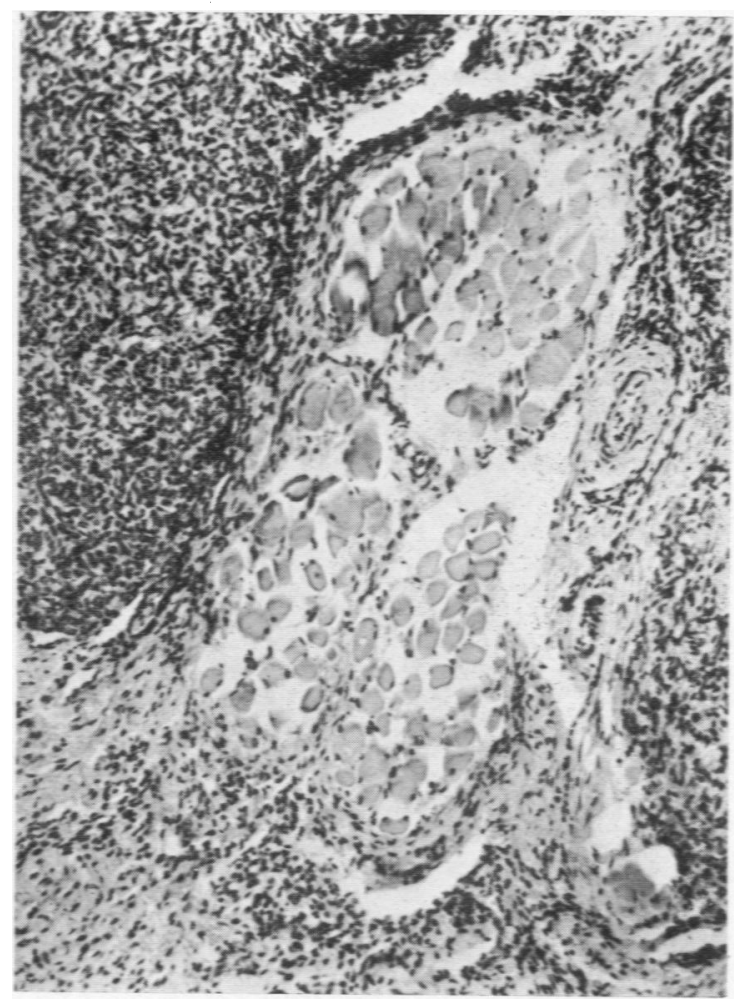

FIG. 11.-Section of haemangio-endothelioma with infiltration into muscle $\times 115$. 
keeping with the short life of these lesions. Either the patient has a 'tendency' to produce showers of haemangiomata or these were benign metastases. The main neck lesion behaved in a manner so like that of the recorded cases that it is claimed to be a haemangio-endothelioma in the absence of biopsy. In this view the case is one of haemangio-endothelioma responding to radiotherapy by disappearing itself and by producing benign metastases.

In all five cases the haemangioma grew early to a large size. In four the site was the soft tissues of the neck, like the possibly related condition of cystic hygroma. In the two that have come to necropsy invasion of deeper structures has caused death. In two of the surviving cases the respiratory tract was obviously obstructed, presumably from pressure or invasion.

Radiological and clinical signs of bone involvement were present in Case 1 and in the case of Kasabach and Merritt (1940). Pack and Miller (1950) state that a haemangioma next to a bone may produce either erosion or local overgrowth, but the changes might have been due to the $x$-ray treatment given.

Thrombocytopenia with prolonged bleeding time was present at some stage in all five cases, associated with purpura and gross haemorrhage into the tumour substance. In our second and in Kasabach and Merritt's case the clotting time was prolonged, possibly owing to a vitamin $\mathrm{K}$ deficiency. The cause of the thrombocytopenia according to Silver et al. may be a failure of the megakaryocytes, which they observed to be somewhat agranular and increased in numbers in the bone marrow. In their case the platelet count was normal during the first 20 months of life and in Case 1 and in that of Kasabach and Merritt the platelet count returned to normal. These findings are against a congenital platelet deficiency, and possibly the process is invasion of the blood vessels by the tumour growth causing haemorrhage so that platelets are used up in the network of the haemangioma, leaving fewer available for the general circulation. The thrombocytopenia and prolonged bleeding time must add greatly to the risks of pressure effects on vital structures, notably the respiratory tract, from sudden enlargement of the haemangioma.

In three of the four cases treated deep x-ray treatment appeared to be effective in reducing the size and encouraging the disappearance of the haemangioma. Blood transfusions were also required to counter anaemia and to lessen the risk of further haemorrhage.

\section{Summary}

Two cases are described in which haemangioendotheliomata in the neck were associated with thrombocytopenic purpura. In both cases haemorrhages occurred into the tumours producing serious respiratory embarrassment. Three similar cases from the American literature are briefly reviewed. Features common to the group are rapid enlargement, invasion of the deeper structures, and $x$-ray changes in underlying bone, recurrent haemorrhage, an accompanying thrombocytopenic purpura, anaemia and prolonged bleeding and clotting times, sensitivity of the tumour to $\mathrm{x}$-rays and perhaps a predilection for the tissues of the neck.

We are grateful to Professor G. F. Hadfield for his advice and help in the gathering together of the material for this paper.

\section{REFERENCES}

Kasabach, H. H. and Merritt, K. K. (1940). Amer. J. Dis. Child., 59,

Pack, G. T. and Miller, T. R. (1950). Angiology, 1, 405.

Rhodes, A. W. and Borrelli, F. J. (1944). Amer. J. Roentgenol., 52, 323. Silver, H. K., Aggeler, P. M. and Crane, J. T. (1948). Amer. J. Dis. Child., 76, 513 .

Stout, A. P. (1943). Ann. Surg., 118. 445. 